\title{
Loucas por livros: as bibliotecárias escolares
}

\author{
Locas por libros: las bibliotecarias escolares \\ Crazy for books: school librarians
}

\author{
Ieda Maria Azevedo ${ }^{1}$ \\ Cristina Maria Rosa ${ }^{2}$ \\ Simone Echebeste ${ }^{3}$
}

\begin{abstract}
Resumo
No artigo apresentamos o Curso de Aperfeiçoamento "Somos Loucos por Livros", cujo foco foi qualificar professores da rede pública municipal de Pelotas que atuam em Bibliotecas Escolares. Composta por 89 escolas - 60 EMEF e 29 EMEI -, a rede conta com professores para as incumbências referentes aos serviços bibliotecários. Nossas referências indicam que a Biblioteca é um espaço destinado a políticas de leitura processos de acesso, uso, fruição e trocas relativas ao artefato mais importante de nossa cultura escrita, o livro. Assim, argumentamos pela premência de que o espaço exista, seja significado pela gestão escolar e ocupado intensamente pelos sujeitos que habitam a escola. Para objetivar a formulação e o desenvolvimento de um diálogo entre Universidade, Secretaria de Educação e Desporto e professores que atuam em Bibliotecas, um grupo de trabalho foi criado em novembro de 2017. Desse, surgiu a proposição de um programa de aperfeiçoamento cujo foco é a formação do mediador em leitura literária na escola. Desenvolvido no ano de 2018, através de um encontro mensal não obrigatório, houve palestras, aulas em livrarias e bibliotecas além de estudos de obras, de autores e gêneros literários. Ao analisar o impacto dessa proposição, intencionamos elencar práticas que oportunizem um aprofundamento nos estudos a respeito da relevância da biblioteca e seus acervos nas escolas.
\end{abstract}

Palavras-chave: Leitura Literária, Bibliotecas escolares; Mediador; Formação de professores.

\section{Resumen}

En el artículo presentamos el Curso de Perfeccionamiento "Somos Locos por Libros", cuyo foco fue calificar profesoras de la red pública municipal de Pelotas que actúan en Bibliotecas Escolares. Compuesta por 89 escuelas - 60 EMEF y 29 EMEI -, la red cuenta con mestres para las incumbencias referentes a los servicios bibliotecarios. Nuestras referencias indican que la Biblioteca es un espacio destinado a políticas de lectura procesos de acceso, uso, fruición e intercambios relativos al artefacto más importante de nuestra cultura escrita, el libro. Así, argumentamos por la premura de que el espacio exista, sea significado por la gestión escolar y ocupado intensamente por los sujetos que habitan la escuela. Para objetivar la formulación y el desarrollo de un diálogo entre la Universidad, la Secretaría de Educación y Profesoras que actúan en Bibliotecas, un grupo de trabajo fue creado en noviembre de 2017. De ahí surgió la propuesta de un programa de perfeccionamiento cuyo foco es la formación del programa, mediador en lectura literaria en la escuela. Desarrollado em el año 2018, a través de un encuentro mensual no obligatorio, hubo charlas, clases en librerías y bibliotecas además de estudios de obras, de autores y géneros literarios. Al analizar el impacto de esta proposición, pretendemos enumerar prácticas que oportunicen una profundización en los estudios acerca de la relevancia de la biblioteca y sus acervos en las escuelas.

Palabras clave: Lectura Literaria, Bibliotecas escolares; mediador; Formación de profesores.

\footnotetext{
${ }^{1}$ Licenciada em Pedagogia; Faculdade de Educação da Universidade Federal de Pelotas; RS; Brasil; kurtzieda@gmail.com

${ }^{2}$ Doutora em Educação Faculdade de Educação da Universidade Federal de Pelotas, RS; Brasil; cris.rosa.ufpel@hotmail.com

${ }^{3}$ Graduada em Bacharel em Biblioteconomia, Universidade Federal do Rio Grande, FURG, Brasil, Simoneechebeste@gmail.com
} 


\begin{abstract}
This paper introduces the development course called "We Are Crazy for Books", which aimed at qualifying teachers who work in libraries that belong to public city schools in Pelotas, RS, Brazil. The school system in this city comprises 89 schools - 60 EMEF and 29 EMEI - where teachers carry out activities related to library services. Our references show that a library is a space which aims at reading policies - processes to access, use, enjoy and exchange the most important artifact in our written culture, i. e., the book. Therefore, we defend that the space must exist, be valued by the school management and intensely occupied by all subjects that inhabit the school. A work group was created in November 2017 to enable a dialogue among Higher Education Institutions, the City Department of Education and teachers that work in libraries. It proposed a development program whose focus was the education of mediators in literary reading in schools. Thus, in 2018, non-mandatory monthly meetings were offered to enable teachers to attend speeches and classes in bookstores and libraries, besides taking part in studies of books, authors and literary genres. The analysis of the impact of this proposal aims at listing practices that may deepen studies of the relevance of libraries and their collections.
\end{abstract}

Key words: Literary Reading; School libraries; Mediator; Teacher Education.

\title{
1.Introdução
}

Tendo como objetivo observar, compreender e discutir a atuação de bibliotecárias escolares como um "fato literário" que pode contribuir para a proposição de políticas de formação do leitor no espaço escolar, no trabalho apresentamos a elaboração e o desenvolvimento de um Curso de Aperfeiçoamento intitulado "Somos Loucos por Livros". O objetivo do curso foi o de qualificar professores da rede pública municipal de Pelotas que atuam em Bibliotecas Escolares e inserir estudantes da Licenciatura em Pedagogia no processo.

Composta por oitenta e nove escolas - sessenta de Ensino Fundamental e vinte e nove de Educação Infantil -, a rede municipal possui apenas três bibliotecárias concursadas: uma atuando na Secretaria de Cultura, outra na Secretaria Municipal de Educação e Desporto e a terceira no Colégio Municipal Pelotense. Na rede de escolarização do município de Pelotas, tanto em escolas urbanas como nas rurais, as incumbências referentes aos serviços bibliotecários ficam a cargo de professores formados em diferentes áreas, entre elas, História, Biologia, Artes, Letras, Educação Física, Pedagogia. São esses profissionais que, por inúmeras motivações, atuam nas salas de leituras ou bibliotecas escolares, organizando, disponibilizando e conservando acervos e procedimentos relativos aos livros didáticos e literários. Parte considerável desses profissionais, no entanto, nunca teve acesso a cursos relativos a atividades biblioteconômicas que inclui políticas de formação do leitor e modos de gerenciamento de acervos e também não cursaram graduação e/ou pós-graduação na área.

Nossas referências indicam que a Biblioteca é um espaço destinado a políticas de leitura - processos de acesso, uso, fruição e trocas relativas ao artefato mais importante de nossa cultura escrita, o livro. Assim, argumentamos pela premência da existência desse 
ambiente em escolas e agregamos o desejo de que, quando presente, que seja significado pela gestão escolar e intensamente usufruído pelos sujeitos que habitam a escola. Defendemos que, nas instituições de Educação Infantil e Ensino Fundamental, a biblioteca deve ser especializada no atendimento a crianças entre zero e quatorze anos de idade, tempo escolar especialmente destinado à formação do leitor.

\section{Bibliotecas: que espaço é esse?}

Dispositivo "complexo, constituído por elementos heterogêneos como a arquitetura e o ambiente, as técnicas e tecnologias, os processos e produtos, as regras e regulamentos, os conteúdos materiais e imateriais", a Biblioteca para crianças e jovens é responsável por ampliar sentidos aos "significados por ela guardados", de acordo com Pieruccini (2002). Entre os pré-requisitos necessários para que ela exista e se configure como "instituição social", Briquet De Lemos (2008, p. 101) lista a "intencionalidade política e social", o "acervo e os meios para sua renovação", a "organização e sistematização", uma "comunidade de usuários, efetivos e potenciais" e, não menos importante, "o local, o espaço físico" onde se dará o encontro entre os usuários, os livros e as políticas de leitura.

Partimos do pressuposto que, entre as ações mais relevantes que ocorrem nesse ambiente está a promoção de situações de leitura para crianças que se encontram "na fase incipiente de contato com a linguagem escrita e que ainda não fazem uso autônomo dessa linguagem" (BAPTISTA, 2014, p. 43). Ao observar o Manifesto pela Biblioteca Escolar (UNESCO, 1999), percebemos que um dos objetivos deste espaço é "desenvolver e manter nas crianças o hábito e o prazer da leitura e da aprendizagem, bem como o uso da biblioteca ao longo da vida".

No Brasil, desde 2010, há uma normativa (Lei $N^{\circ}$ 12.244) que determina a existência de bibliotecas em instituições de ensino (BRASIL, 1998). Apesar da relevância pedagógica da biblioteca, de acordo com Neves (2010), “esse ambiente escolar em geral tem sido desprezado pelas políticas públicas e pelas práticas docentes". Waldeck Carneiro da Silva aborda o tema em Miséria da Biblioteca Escolar (1995). No texto, o autor expõe a realidade das escolas brasileiras: “... quando existe biblioteca, esses lugares não passam de depósitos de livros e de outros objetos, com horários de funcionamento breves e irregulares, ou ainda são convertidas em espaços de punição". Sobre o mesmo tema, Neves é clara quando considera que, em muitas escolas, as bibliotecas acabam "cumprindo mais a função de depósito de livros e materiais do que de ambiente pedagógico para informação, letramento e fruição" (NEVES, 2010). 
Espaço único, imprescindível, que não pode faltar na estrutura educativa, a Biblioteca Escolar e nela, as políticas de formação são fundamentais para o surgimento de leitores literários a quem o gosto pelo livro e seus atributos deve ser ensinado desde muito cedo. $\mathrm{Na}$ biblioteca, ainda, é necessário a presença e a atitude organizada e constante do mediador, ou seja, a deliberada ação do adulto - bibliotecário, pedagogo, professor - na promoção do encontro entre livro e leitor, a fim de que este "estabeleça com o texto lido uma interação prazerosa", de acordo com Paulino (2014, p. 177).

\section{Leitura}

Fenômeno que extrapola os sujeitos em relação, a leitura não se restringe ao ato de decodificar letras, sílabas e construções frasais utilizadas em gêneros textuais dos mais diversos tipos. Assim, não está circunscrita ao ato de relacionar sons e sinais gráficos inventados historicamente pela humanidade, capazes de produzir compreensão, interpretação, conotação ou suposição de intenções. Mais que isso, a leitura antecede a primeira relação preconizada na escola - compreender o sistema alfabético, suas regras e manifestações. E, por isso, é um fenômeno e não apenas uma habilidade.

A leitura é um fenômeno que ocorre em quatro dimensões: anterior à decodificação do sistema de escrita alfabético, concomitante a sua aprendizagem e posterior a suas descobertas. É ainda, um fenômeno de dimensão imensurável, inimaginável e magnífico, especialmente pela sua capacidade inventiva. Ao nascer em uma sociedade leitora, cada humano recebe, desta e como herança cultural a ser apreendida e incorporada, cultuada, rejeitada, acentuada, ampliada ou simplesmente ignorada, um rol de saberes sobre o que é, qual a importância, valor e função da escrita e como é possível conhecê-la e utilizá-la. Assim, pode ser entendida como um fenômeno cultural que ocorre no tempo - na história de cada de leitor - e no espaço, geográfico, mas também social, para o qual concorrem muitos elementos.

Como fenômeno anterior à compreensão do sistema de escrita alfabético, a condição leitora se abastece nos saberes que circulam acerca do valor social da leitura. Assim, é possível afirmar que é uma faculdade a ser adquirida. E é uma capacidade que ocorre processualmente, por toda a vida e antecede o conhecimento de letras e suas combinações, aprimorando ou prejudicando a compreensão do sistema alfabético.

Concomitante à compreensão do sistema de escrita alfabético, a leitura é um fenômeno exatamente pela concomitância, ou seja, enquanto se lê é que ocorre a compreensão da escrita em si, seu valor gramatical, gráfico, correspondente, representativo, posicional e 
conceitual. Conhecer e compreender o sistema de escrita alfabética é condição para a leitura, mas não se restringe a ela.

Além disso, a leitura é um fenômeno posterior, pelo poder que possui de reverberar sentidos e significados na vida do leitor. E, por fim, é um fenômeno que produz uma dimensão imensurável - a inventiva - quando do contato com a escrita literária, uma vez que esta agrega ao produto da escrita convencional, o valor da arte do escrito. Para Arthur Schopenhauer (2003), “a experiência pessoal é a condição indispensável, necessária para a compreensão tanto da poesia quanto da história, pois é, por assim dizer, o dicionário da língua falada por ambas". Mais difícil de ser observada, a dimensão inventiva oferece indícios quando das comunicações orais ou escritas (discursos, uso do léxico, composições e elucubrações) por seus usuários.

\section{A leitura na biblioteca da escola}

O livro - esse instrumento sem o qual não posso imaginar minha vida e que não me é menos íntimo do que minhas mãos e meus olhos. (...) O livro é uma extensão da memória e da imaginação (BORGES, 2001, p. 188-189).

Instituição criada historicamente com uma função social, a escola simboliza e materializa um espaço público e uma possibilidade de acesso ao conhecimento. E é na escola que a maior parte das crianças acessa a cultura escrita, representada por todos os impressos considerados importantes para uma determinada sociedade.

Ouvir histórias lidas, desde há muito tempo é um hábito que envolve prazer, instrução e informação. Reunir-se para ouvir alguém ler tornou-se também uma prática necessária na Idade Média, pois, segundo Manguel (1999), até a invenção da imprensa, a alfabetização era rara e os livros, propriedade dos ricos, privilégio de um pequeno punhado de leitores. Assim, pessoas que desejavam ter acesso a algum livro que apreciassem tinham mais oportunidade de ouvir o texto "recitado ou lido em voz alta do que de segurar o precioso volume nas mãos" (MANGUEL, 1999, p. 138).

Em tempos digitais, o primeiro contato com a leitura nem sempre se faz com a literatura. Em tablets ou telefones celulares, a maioria das crianças, demora consideravelmente para saber o que é, para que serve e como se faz para usufruir de um livro de literatura. Além disso, em ocasiões eventuais como visitas a bibliotecas públicas, feiras do livro e livrarias, é comum o contato com contações de história e não leitura de histórias. No entanto, contar e ler são duas atitudes diferenciadas, com peculiaridades que indicam o tipo de interação que cada uma produz nos sujeitos. 
A alfabetização literária, por sua vez, é um processo deliberado, frequente e qualificado de apresentação da leitura, seus atributos e ritos a todas as crianças e desde que iniciam sua vida escolar. Justificamos a urgência desse processo na vida das crianças fundada na certeza de que essa é uma habilidade referencial à vida dos humanos em sociedade, além de integrar os saberes docentes, qualificar o processo de aquisição da linguagem oral e inserir as crianças pequenas na cultura escrita. Para alfabetizar literariamente, é preponderante a atitude de um mediador - uma pessoa que "estende pontes entre os livros e os leitores" (REYES, 2014).

\section{Literatura: arte de viver}

A literatura é uma arte. Para quem escreve e para quem frui. É um fenômeno da criatividade, para Nelly Novaes Coelho (1991). Um direito ainda não escrito, para Bartolomeu Campos de Queirós. É a literatura que nos faz humanos e só a ficção nos salva, disse Tzvetan Todorov (2010). A literatura integra a cultura escrita, uma de nossas maiores conquistas antropológicas. A literatura é uma experiência estética, cujo resultado seu criador quer fazer único e inconfundível, com marcas que ele gostaria que fossem percebidas pelo leitor como pegadas no caminho da leitura, de acordo com Maria Antonieta Antunes Cunha (2014).

A literatura pressupõe assumir que a linguagem é uma "faculdade cognitiva exclusiva da espécie humana que permite a cada indivíduo representar e expressar simbolicamente sua experiência de vida" (BAGNO, 2014, p. 192). É uma das formas de produzir sentido e pode ser conceituada como "um fenômeno social, uma forma de ação e de interação social”. Assim, "produzir um texto significa dizer algo a alguém, por algum motivo, de algum modo, em determinada situação" (FIAD \& VAL, 2014, p. 264).

A literatura exige um "leitor proficiente", aquele que não só "decodifica as palavras que compõem o texto escrito", mas, também, "constrói sentidos de acordo com as condições de funcionamento do gênero em foco". Para tal, mobiliza "um conjunto de saberes sobre a língua", representado por "outros textos, o gênero textual, o assunto focalizado, o autor do texto, o suporte e os modos de leitura", de acordo com Da Mata (2014, p. 165).

A literatura e sua fruição demandam um experiente da espécie que, ao exercer o ofício de mediador, "crie as condições para fazer com que seja possível que um livro e um leitor se encontrem", em "rituais, momentos e atmosferas propícias" (REYES, 2014, p.213). A literatura é uma experiência estética literária como a soma da percepção/apreensão inicial de 
uma criação literária e das muitas reações (emocionais, intelectuais ou outras) que esta suscita (...) para Maria Antonieta Antunes Cunha (2014).

A leitura de literatura é um "modo muito singular de construir sentidos". Oportuniza uma "intensidade" de interação com "a palavra que é só palavra" e uma experiência "libertária de ser e viver”, de acordo com Rildo Cosson (2014, p. 185) e a escrita literária tem três características fundamentais: "ela é coisa na/da linguagem, aquilo que na/da linguagem não é discurso, mas silêncio", a escrita ou a leitura de um texto literário "é uma actividade que rompe (no sentido violento) o laço social" e, esta ruptura "tem um alcance e um valor sexuais", de acordo com Cristina Álvares (2004, p. 1).

A leitura de literatura é uma experiência rigorosamente pessoal para o leitor quanto a criação é para seu autor (CUNHA, 2014) e, para Paulino (2014), é uma "Prática cultural de natureza artística", pois a leitura do texto literário se diferencia por oportunizar contato com "outros mundos, em que nascem seres diversos, com suas ações, pensamentos, emoções". Nas palavras de Todorov (2013): “A importância da Literatura não é o método ou teoria com a qual a estudamos, mas é a própria Literatura. Porque ela fala de nós mesmos, da condição humana, da nossa sociedade. Ela nos permite compreender melhor o mundo. Quando lemos um livro, está lá o que é mais importante”.

Mas, ler é diferente de contar.

Não é mais, nem menos. É diferente. Na escola, a criança - aprendiz da espécie humana que através da fala e pela escrita aprende a organizar o pensamento - acessa, com a audição de histórias lidas, contatos e aprimoramentos das relações com a cultura escrita, uma de nossas maiores conquistas antropológicas. Ler para os pequenos desde tenra infância, é inserir a todos no que de melhor produzimos como "sapiens": a escrita autoral ou, um modo particular de ver/sentir/narrar o mundo e, um bom mediador, dá nome a quem de direito: ao autor, a autoria; ao mediador, os sentimentos todos que encontrou ali e quer perpetuar, divulgar, evidenciar.

No texto Experiência e Pobreza, o filósofo Walter Benjamin (1933), disserta sobre a perda da capacidade de contar histórias - e de, com elas, dar ensinamentos morais através do intercâmbio de experiências -, ocasionada pela dissolução dos vínculos familiares e pelo empobrecimento de experiências comunicáveis da população. Gustavo Bernardo elaborou o "seu" conceito de literatura e o publicou, com outros pesquisadores, na obra Introdução aos termos literários, organizada por José Luis Jobim (2002). Para Bernardo (2002), 
A ficção, a literatura, fazem mais do que ampliar as nossas perspectivas, ao mapearem a realidade, anunciando territórios inexplorados e desconhecidos; a ficção e a literatura nos permitem viver o que de outro modo talvez não fosse possível, ou seja, nos permitem ser outros (os personagens) e adquirir, ainda que momentaneamente, a perspectiva destes outros - para, adiante, termos uma chance de cumprir o primado categórico de todas as éticas, de tão difícil realização: ser o que se é".

\section{Conclusões}

Para objetivar a formulação e o desenvolvimento de um diálogo entre Universidade, Secretaria de Educação e Desporto e Professores que atuam em Bibliotecas, em parceria inédita e por sugestão dos interessados, um grupo de trabalho foi criado em novembro de 2017. Desse, surgiu a proposição de um programa de aperfeiçoamento cujo foco é a formação do mediador em leitura literária na escola. Desenvolvido no ano de 2018, através de um encontro mensal não obrigatório, há no curso "Somos Loucos por livros!" atividades como palestras, aulas em livrarias e bibliotecas além de estudos de obras, de autores e gêneros literários.

O primeiro passo ocorreu entre 02 de dezembro de 2017 e 02 de março de 2018: as reuniões preparatórias ao Curso de Aperfeiçoamento "Somos loucos por livros". A equipe, coordenada pela Docente da Faculdade de Educação da UFPel Dr ${ }^{a}$ Cristina Maria Rosa e pela Bibliotecária da SMED Simone Echebeste, foi complementada com a participação da Pedagoga Estela Maria da Rocha Sampaio, pelas professoras Ellen Borba, Daniela Castro e Simone Conti e pelas estudantes Alessandra Steilmann, Cinara Postringer, Ieda Kurtz, Érica Leopoldo, Rafaela Camargo e Tamires Machado.

Entre 02/03 a 10/11/2018, ocorreu a oferta do curso que, inicialmente sugeriu como temas os seguintes tópicos: 1) Repertório e Acervo: leitura e diálogo; 2) Ambientação de bibliotecas e Espaços para leitura; 3) Acervos de literatura brasileira nas bibliotecas; 4) Antologia de textos literários; 5) Antologia de Poemas Brasileiros; 6) Elaboração de um Projeto de Leitura; 7) Critérios de Escolha de obras Literárias; 8) Os gêneros literários; 9) Visita à Feira do Livro; 10) Leitura do Acervo do Curso de Aperfeiçoamento; 11) Avaliação Oral, Encerramento e Entrega dos certificados. Todos os temas foram abordados de forma oral dialogada e mediados por obras literárias que foram lidas, observadas, fotografadas, apreciadas e analisadas pelos presentes. Entre 10/11 e 10/12/2018 houve avaliações pela equipe propositora e com os professores que integraram o público do curso.

Entre os resultados, a aceitação por parte considerável de professores que atuam em Bibliotecas, a frequência dos inscritos aos encontros e o convencimento de que é necessário 
realizar uma avaliação qualitativa tanto do programa ofertado como das expectativas dos participantes. Ao analisar o impacto dessa proposição, intencionamos elencar práticas que oportunizem um aprofundamento nos estudos a respeito da relevância da biblioteca e seus acervos nas escolas. Coordenado pelo GELL - Grupo de Estudos em Leitura Literária da Universidade Federal de Pelotas - o inédito curso é partilhado com a SMED Pelotas e se faz acompanhar de processo de avaliação pelo público alvo, com vistas a estabelecer um diálogo frequente e sem data para conclusão entre os envolvidos.

\section{Referências}

ÁLVARES, C. in: COSSON, R. Glossário CEALE: UFMG/CEALE, 2014.

BEBETECAS. In: BAPTISTA, Mônica. Glossário Ceale: Termos de alfabetização, leitura e escrita para educadores. Belo Horizonte: UFMG/Faculdade de Educação. Disponível em: $<$ http://ceale.fae.ufmg.br/app/webroot/glossarioceale/verbetes/bebetecas-bibliotecas-para-aprimeira-infancia>. Acesso em: 06/07/2018.

BENJAMIN, W. O Narrador. Considerações sobre a obra de Nicolai Leskov. In: Magia e técnica, arte e política: ensaios sobre literatura e história da cultura. São Paulo: Brasiliense, 1994.

BERNARDO, G. Conceito de literatura. In: JOBIM, J. L. Org). Introdução aos termos literários. Rio de Janeiro: Editora 34, 2002.

BORGES, J. L. Obras Completas IV. São Paulo, Globo, 2001.

BRASIL. MEC/FNDE. Manual pedagógico da biblioteca da escola. Brasília: FNDE, 1998. Disponível em: <http://portal.mec.gov.br/programa-nacional-biblioteca-da-escola>. Acesso em: 18/06/2018.

BRIQUET DE LEMOS, A.A. Excerto. In: CAMPELO, B. Biblioteca escolar como espaço de produção do conhecimento: Parâmetros para bibliotecas escolares. Belo Horizonte: Autêntica, 2010.

COELHO, N. N. Literatura Infantil: teoria, análise, didática. São Paulo: Moderna, 2000.

EXPERIÊNCIA ESTÉTICA LITERÁRIA. In: CUNHA, M. A. A. Glossário Ceale: Termos de alfabetização, leitura e escrita para educadores. Belo Horizonte: UFMG/Faculdade de Educação.

Disponível em: 
http://www.ceale.fae.ufmg.br/app/webroot/glossarioceale/verbetes/experiencia-esteticaliteraria. Acesso em: 09/06/2018.

FIAD, R. \& VAL, M. Produção de textos. Glossário Ceale: termos de alfabetização, leitura e escrita para educadores. Belo Horizonte: UFMG/Faculdade de Educação, 2014.

LEITOR PROFICIENTE. In: DA MATA. M. A. Glossário Ceale: Termos de alfabetização, leitura e escrita para educadores. Belo Horizonte: UFMG/Faculdade de Educação. Disponível em: < http://www.ceale.fae.ufmg.br/app/webroot/glossarioceale/verbetes/leitor-proficiente>. Acesso em: 11/2018.

LETRAMENTO LITERÁRIO. In: COSSON, R. Glossário Ceale: Termos de alfabetização, leitura e escrita para educadores. Belo Horizonte: UFMG/Faculdade de Educação. Disponível em: 〈http://www.ceale.fae.ufmg.br/app/webroot/glossarioceale/verbetes/letramento-literario>. Acesso em: 06/07/2018.

LINGUAGEM. In: BAGNO, M. Glossário Ceale: Termos de alfabetização, leitura e escrita para educadores. Belo Horizonte: UFMG/Faculdade de Educação. Disponível em: <http://www.ceale.fae.ufmg.br/app/webroot/glossarioceale/verbetes/linguagem>. Acesso em: 07/07/2018.

MANGUEL, A. Uma história da leitura. São Paulo: Companhia das Letras, 1999.

MEDIAÇÃO LITERÁRIA In: REYES, Y. Glossário Ceale: Termos de alfabetização, leitura e escrita para educadores. Belo Horizonte: UFMG/Faculdade de Educação. Disponível em: < http://www.ceale.fae.ufmg.br/app/webroot/glossarioceale/verbetes/mediadores-de-leitura>.

Acesso em: 07/06/2018.

NEVES, N. V.; RAMOS, F. B. O espaço da Biblioteca Escolar: análise das condições de mediação de leitura. In: Congresso International de Filosofia e Educação. Eixo Temático: 08 - Educação e Linguagem. Caxias do Sul: UCS, 2010. Disponível em: <http://www.ucs.br/ucs/eventos/cinfe/artigos/artigos >. Acesso em: 21/06/2018.

PAULINO, G. Saberes literários como saberes docentes. Revista Presença Pedagógica v.10 n.59. set/out. 2004.

PIERUCCINI, I. Excerto. In: CAMPELO, B. Biblioteca escolar como espaço de produção do conhecimento: Parâmetros para bibliotecas escolares. Belo Horizonte: Autêntica, 2010.

QUEIRÓS, B. C. de. Manifesto por um Brasil literário. Disponível em: <http://www.brasilliterario.org.br/manifesto/o-manifesto/>. Acesso em: 26/08/2018 
SCHOPENHAUER, A. Metafísica do Belo. UNESP: Editora da UNESP, 2003.

SILVA, W. C. Miséria da biblioteca escolar. São Paulo: Cortez, 1999.

TODOROV, T. Literatura não é teoria, é paixão. Entrevista concedida a Anna Carolina Mello e André Nigri. Revista Bravo, fevereiro de 2010, páginas 38-39.

UNESCO. Manifesto IFLA/UNESCO para biblioteca escolar. Tradução de Neusa Dias Macedo. São Paulo, 2000. Disponível em:<http://archive.ifla.org/VII/s11/pubs/portuguesebrazil.pdf>.Acesso em: 21/07/2018. 